\title{
Air-to-water heat pump assessment: Part 1 - Experimental setup
}

\author{
Nadezhda Doseva ${ }^{1,{ }^{*}, \text { Daniela } \text { Chakyrova }^{1} \text {, Svetoslav Stoianov }}{ }^{1}$, and Ilia Hadhidimov ${ }^{1}$ \\ ${ }^{1}$ Varna Technical University, Heat Technology Department, 9000 Varna, Bulgaria
}

\begin{abstract}
This paper is part 1 of the investigation on the exergetic and exergoeconomic parameters of an existing system with an air-to-water heat pump unit as a heat source. Part 1 presents the used experimental setup. The main aim of the conducted experimental tests is to develop a model of produced heat transfer rate and energetic $C O P$ at different ambient conditions. The obtained data is used in Part 2 of the study where the exergetic and exergoeconomic assessment is carried out. The performance of the considered system is evaluated using Seasonal Exergy Efficiency. Moreover, Part 2 of the study has presented the formulation of the cost of the product, and cost allocation within the heat pump unit based on exergy.
\end{abstract}

\section{Introduction}

In the reference literature, there is a wide discussion about the performance parameters of air-to-water heat pumps (AWHP). In many studies is conducted experimental and theoretical research on the factors that affected the coefficient of performance $(C O P)$ of an aerothermal heat pump and consumed electrical energy. For example, Zhao et al. [1] conduct the experimental study of an aerothermal heat pump and they establish the influence of the water temperature in the tank on the observed COP of the heat pump when the external air temperature remains almost constant.

Morrison et al. [2] determined experimentally the consumed electrical energy and instantaneous heat capacity for the considered in cited investigation types of the heat pump system. The experiment is carried out for a range of ambient temperature and relative humidity conditions and the aim of the study is to demonstrate the procedure for seasonal performance rating of air-source heat pump water heaters. Ji et al. [3] conduct a laboratory test of an AWHP with the utilization of the rejected heat in cooling mode. The experiment is conducted to validate the developed model of the system's performance. Another part of studies in reference literature deals with experimental and theoretical research of novel airto-water heat pump systems [4-6].

While many authors are conducting experiments to establish specific dependencies, which characterized air-to-water heat pumps, little is known about necessary output data for the conduction of dynamic exergy and exergoeconomic analysis of a real aerothermal heat pump system. Ozturk et al. [7] investigated experimentally an AWHP from the exergy point of view. The objective of the experimental test is to collect the data for the

\footnotetext{
* Corresponding author: nadezhda.doseva@abv.bg
} 
thermodynamic properties of the working fluids of the system at specific states and to evaluate the exergy destruction of the system's components at varying ambient conditions.

In this regard, the current paper suggests the simplified method for experimental research of an existing AWHP system, considering the system as a black-box with defined inputs and outputs. Thus, the used equipment, instruments, and realized measurements are minimized, because the parameters at the internal state of the refrigerant are not necessary to know. The study aims to establish the dependencies between specific system performance parameters (produced heat transfer rate and energetic $C O P$ ) and dynamic changing ambient conditions. The obtained data is used in Part 2 of the study where the exergetinc and exergoeconomic assessment is carried out.

\section{Air-to-water heat pump experimental setup}

To determine the electrical energy input to the AWHP unit and produced heat transfer rate at different ambient conditions, an air-to-water heat pump experimental platform is developed. The experimental setup consists of instruments for the AWHP operating parameters data acquisition and displaying in real-time. The measurements were implemented in the period 09.02-22.02.2020. The general view of the system and schemes of the AWHP experimental setup are shown in Figure 1, 2 and 3, respectively.

\subsection{Description of the equipment and instruments for the AWHP operating parameters data acquisition and displaying in real-time}

The AWHP system (Figure 2) is an existing system located in Varna Technical University, Bulgaria - at the laboratory of the Heat Technology Department. The AWHP unit is split type, model PUHZ-SW75VHA(-BS)\ERSC-MEC (Mitsubishi). The heat pump unit is the inverter-driven, reversible type and with a variable outlet (according to the classification of EN 14825:2019). The outdoor (OU) and the ERSC-MEC indoor (IU) units are mounted on both sides of the laboratory's eastern facade. The refrigerant is R410A. The heat transfer medium is a $30 \%$ water solution of propylene glycol.

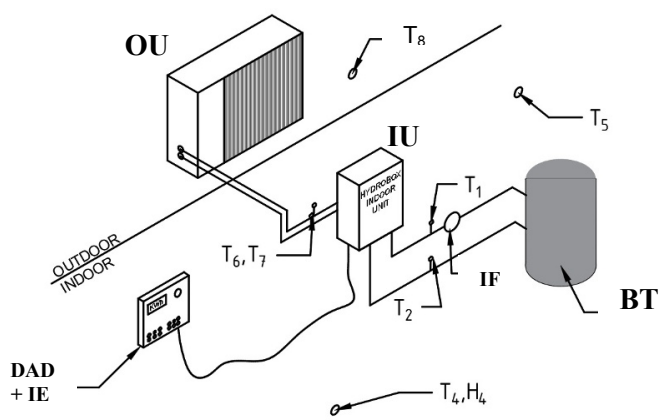

Fig. 1. Scheme of the AWHP experimental platform: DAD+IE -instruments for data acquisition and displaying in real-time + static single-phase electric meter; BT - buffer tank with 80 litres volume; OU - outdoor heat pump unit; IU - indoor heat pump unit; IF - water flow meter with Hall effect sensor; $\mathrm{T}_{1}, \mathrm{~T}_{2}, \ldots, \mathrm{T}_{8}$ - digital thermometers; $\mathrm{H}_{4}$ - relative humidity sensor. 


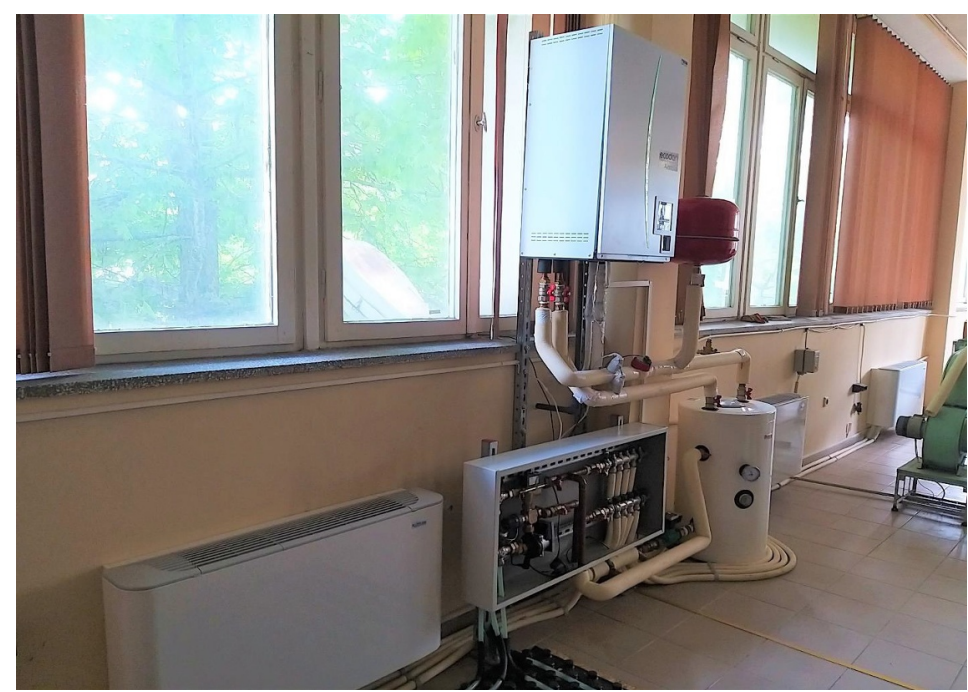

Fig. 2. General view of the AWHP system.

In addition, the AWHP system consists of four fan coil units with a nominal heat transfer rate of $5.7 \mathrm{~kW}$ (i.e., at the nominal value of logarithmic meant temperature difference $\Delta T_{\text {nom }}=50 \mathrm{~K}$ or at $75^{\circ} \mathrm{C} / 65^{\circ} \mathrm{C} / 20^{\circ} \mathrm{C}$ ).

Figure 2 presented the location of the all of the used digital thermometers and equipment. The wire digital thermometers provide from 9-bit to 12-bit Celsius temperature measurements. $T_{1}$ and $T_{2}$ measure the temperature of the glycol solution inlet and outlet to the indoor unit (i.e., they measure the temperatures $t_{w, e}$ and $t_{w, i}$, respectively). The digital thermometers $T_{1}$ and $T_{2}$ and are mounted on the supply and return pipe - before the buffer tank (BT). The digital thermometers $T_{6}$ and $T_{7}$ quantify the temperature of refrigerant flows. The scheme of the observed AWHP unit and location of the digital thermometers $T_{1}, T_{2}, T_{6}$, and $T_{7}$ is presented in Figure 3.

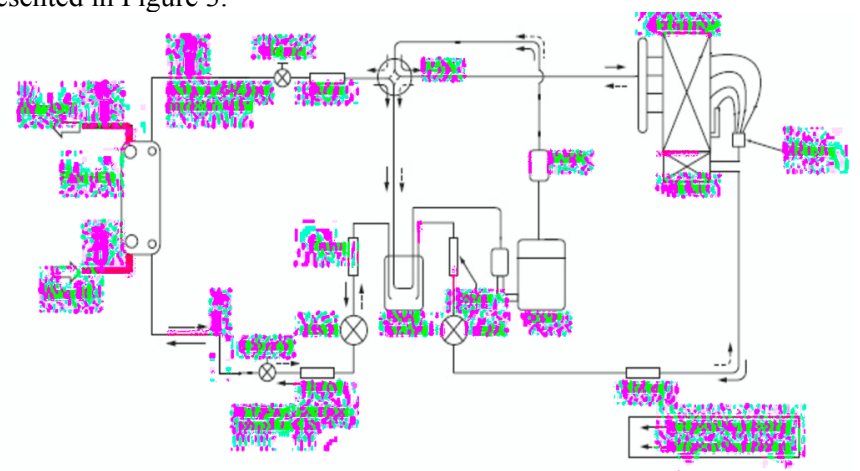

Fig. 3. Scheme of the observed AWHP unit [8]: HEX - heat exchanger; Comp - compressor; LEV-A and LEV-B - linear expansion valve; REV/V - reversible valve; $\mathrm{T}_{1}$ and $\mathrm{T}_{2}$ - digital thermometers measured water-glycol solution temperature; $\mathrm{T}_{6}$ and $\mathrm{T}_{7}$ - digital thermometers measured refrigerant temperature 
The indoor air temperature is measured in two points: near to the wall $\left(T_{5}\right)$ and into the room - through combined humidity and temperature sensor $\left(T_{4}, H_{4}\right)$. The outdoor air digital thermometer $\left(T_{8}=t_{e}\right)$ is located on the eastern facade of the room, and it is protected from direct solar radiation and wind.

The flow rate of the glycol solution is measured by a single jet, dry dial liquids flow meter with a Hall effect sensor. The flow meter is velocity type, with the impeller mounted in radial position within the body of the flowmeter, whereas the incidence of the liquid flow is tangential. The liquids flow meter is mounted in the circuit of the indoor unit and buffer tank, on the supply water pipe of the system - in a horizontal position. The maximum pressure loss of the liquids flow meter is 0.63 bar (i.e., $\Delta \mathrm{p} 63$ ) at volumetric flow rate with value within the interval of the minimal $\left(Q_{1}=40 \mathrm{l} / \mathrm{h}\right)$ and permanent flow rate $\left(Q_{3}=4 \mathrm{~m}^{3} / \mathrm{h}\right)$. Therefore, the measuring range of the liquids flow meter is $Q_{3} / Q_{1}=100(\mathrm{R} 100-\mathrm{H})$. The declared maximum permissible error (MPE) on volumes between the minimum flow rate $\left(Q_{1}\right)$ and the transitional flow rate $\left(Q_{2}=641 / \mathrm{h}\right)$ is $\pm 5 \%$, whereas on volumes between the transitional flow rate $\left(Q_{2}=64 \mathrm{l} / \mathrm{h}\right)$ and the overload flow rate $\left(Q_{4}=5 \mathrm{~m}^{3} / \mathrm{h}\right)$ the declared MPE is $\pm 3 \%$. The temperature range of the flow meter is $30 \div 90^{\circ} \mathrm{C}$.

The consumed electrical energy from the AWHP unit and the auxiliary elements is measured through the static electric meter. It is designed for the measurement and registration of active energy in single-phase two-wire networks for direct connection. The rated voltage of the electric meter is $230 \mathrm{~V}$ and the basic (reference) current is $I_{b}=10 \mathrm{~A}$. The electric meter has a built-in LED indicator, reproduces a pulse with a width of $40 \mathrm{~ms}$ when it read $1 \mathrm{Wh}$ electrical energy. The electrical pulse enters the instruments for data acquisition and displays in real-time.

The accuracy and tolerance of the used types of equipment are summarized in Table 1.

Table 1. The accuracy and tolerance of the used equipment.

\begin{tabular}{|c|c|c|c|c|}
\hline Equipment & Symbol & Declared accuracy & Full scale & Model \\
\hline $\begin{array}{c}\text { Digital } \\
\text { thermometers }\end{array}$ & $\begin{array}{c}\mathrm{T}_{1}, \mathrm{~T}_{2} \mathrm{~T}_{3}, \\
\mathrm{~T}_{5}, \mathrm{~T}_{6}, \\
\text { and } \mathrm{T}_{7}\end{array}$ & $\pm 0.1^{\circ} \mathrm{C}$ & $-10{ }^{\circ} \mathrm{C} \div 85^{\circ} \mathrm{C}$ & DS18B20 \\
\hline $\begin{array}{c}\text { Combined digital } \\
\text { thermometer and } \\
\text { humidity sensor }\end{array}$ & $\mathrm{T}_{4}, \mathrm{H}_{4}$ & $\begin{array}{c}\text { Humidity: } \pm 2 \% ; \\
\text { Temperature: } \pm 0.5^{\circ} \mathrm{C}\end{array}$ & $\begin{array}{c}\text { Humidity: } \\
0 \% \div 100 \% \\
\text { Temperature: } \\
-10^{\circ} \mathrm{C} \div 85^{\circ} \mathrm{C}\end{array}$ & DHT22 \\
\hline $\begin{array}{c}\text { Liquids flow } \\
\text { meter with Hall } \\
\text { effect sensor }\end{array}$ & IF & $\begin{array}{c} \pm 3 \% \text { at } 64 \mathrm{l} / \mathrm{h}<Q<5 \mathrm{~m}^{3} / \mathrm{h} \\
\pm 5 \% \text { at } 40 \mathrm{l} / \mathrm{h}<Q<64 \mathrm{l} / \mathrm{h}\end{array}$ & $40 \mathrm{l} / \mathrm{h} \div 4 \mathrm{~m}^{3} / \mathrm{h}$ & $\begin{array}{c}\text { B-METERS } \\
\text { GSD8-RFM }\end{array}$ \\
\hline $\begin{array}{c}\text { Static single } \\
\text { phase electric } \\
\text { meter }\end{array}$ & IE & $\pm 2 \%$ at $0.1 \mathrm{I}_{\mathrm{b}}<\mathrm{I}<\mathrm{I}_{\max }$ & $\begin{array}{c}0.5 \mathrm{~A} \div 85 \mathrm{~A} \\
0.8 \mathrm{U}_{\mathrm{n}} \div 1.25 \mathrm{U}_{\mathrm{n}}\end{array}$ & ISKRA \\
ME161 \\
\hline
\end{tabular}

The system for data acquisition and displaying in real-time is based on the Arduino UNO platform, consisting of an 8-bit AVR microcontroller. A schematic diagram of the system is shown in Figure 4. The system consists of the following additional elements:

- SD and Real-Time Clock - this module can record data on an SD card, while the clock acquisition data about time and date;

- 16x2 LCD display and keyboard - the module is used for displaying the data in realtime. It allows the selection of visualization of another operation parameter using the keys on the keyboard. 


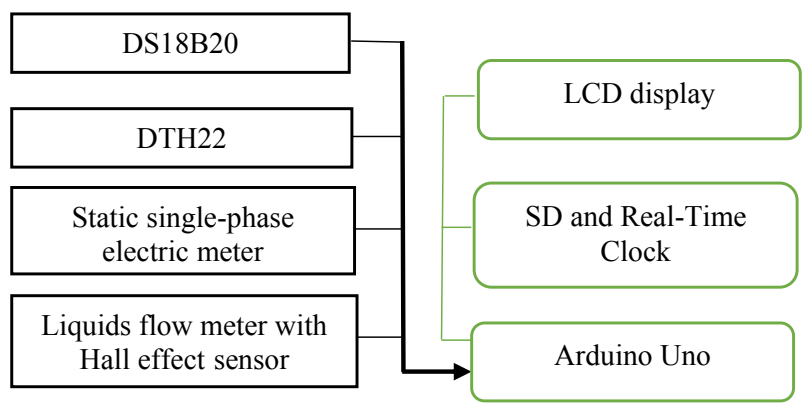

Fig. 4. Scheme of the system for data acquisition and displaying in real-time.

The measured parameters were recorded every 1 minute. The ultimate operating parameters are the average statistics for the 30 minutes.

\subsection{Identifying the outliers}

In the current paper, for outliers filtering is used Chauvenet's criterion. To identifying the outliers, first, the data is grouped according to the outside air temperature, $t_{e}$. Within the $i$-th external air temperature bin, $t_{e} \pm 0.5^{\circ} \mathrm{C}$, it is observed $n$ measurements of $x_{i}(i=1,2, \ldots, n)$ that have a mean, $\bar{x}$, and sample standard deviation, $S$. From point of view of Chauvenet's criterion, the measurements that should be rejected are those that have the probability of obtaining their deviation from the mean is less than $1 /(2 n)$. This statement is expressed by the equation [9]:

$$
\text { if }\left|\frac{x_{i}-\bar{x}}{S}\right|<\tau_{\max } \text {, then reject } x_{i}
$$

The maximum acceptable normalized deviation, $\tau_{\max }$, for various values of the number of measurements $(n)$ is determined according to the look-up table [10].

In equation (1), the terms mean, $\bar{x}$, and sample standard deviation, $S$, are determined as follow [10]:

$$
\begin{gathered}
\bar{x}=\frac{x_{1}+x_{2}+\ldots+x_{n}}{n}=\sum_{i=1}^{n} \frac{x_{i}}{n} \\
S=\sqrt{\sum_{i=1}^{n} \frac{\left(x_{i}-\bar{x}\right)^{2}}{(n-1)}}
\end{gathered}
$$

\subsection{Uncertainty analysis}

After the outliers were identified and rejected, the uncertainty analysis of the obtained mean values was conducted. The current experimental measurements aim to establish the mathematical models of the produced heat power and energetic $C O P$ of the observed AWHP. Consequently, the objective of this analysis is to assess the translation of the uncertainties from the individual measurement into the uncertainty in the final results for $Q$ and $C O P$ at an external air temperature bin, $t_{e} \pm 0.5^{\circ} \mathrm{C}$. 
In the current paper, the data from individual measured variables $x_{1}, x_{2}, \ldots, x_{n}$ are combined to determine the final results for $Q$ and $C O P$. Therefore, the systematic uncertainty of the mean values of the parameter $R$ is determined through the conceptual basis of the root of the sum of the squares [10]:

$$
B_{R}=\left\{\sum_{i=1}^{N}\left(B_{i} \frac{\partial R}{\partial x_{i}}\right)^{2}\right\}^{1 / 2}
$$

According to the equation (4), the systematic uncertainty of the mean values of the $Q$ and $C O P$ is:

$$
\begin{gathered}
B_{Q}=\left[\left(B_{V} \frac{\partial Q}{\partial V}\right)^{2}+\left(B_{T_{w i}} \frac{\partial Q}{\partial T_{w i}}\right)^{2}+\left(B_{T_{w i}} \frac{\partial Q}{\partial T_{w e}}\right)^{2}+\left(B_{\rho} \frac{\partial Q}{\partial c_{p} \rho}\right)^{2}\right]^{1 / 2} \\
B_{C O P}=\left[\begin{array}{l}
\left.\left(B_{V} \frac{\partial C O P}{\partial V}\right)^{2}+\left(B_{T_{w i}} \frac{\partial C O P}{\partial T_{w i}}\right)^{2}+\left(B_{T_{w i}} \frac{\partial C O P}{\partial T_{w e}}\right)^{2}+\right]^{1 / 2} \\
+\left(B_{c_{p}} \frac{\partial Q}{\partial c_{p} \rho}\right)^{2}+\left(B_{W_{e l}} \frac{\partial C O P}{\partial W_{e l}}\right)^{2}
\end{array}\right.
\end{gathered}
$$

In equations (5a) and (5b) the partial derivatives $\partial Q / \partial \rho c_{p}$ and $\partial C O P / \partial \rho c_{p}$ are involved because they are not considered as a constant when the temperature of the waterglycol solution vary. The similar approach is used in [11]. It is important to note, that the volumetric flow rate, $V$, temperatures of the heat transfer medium, $T_{w e}$ and $T_{w i}$, and electrical power, $W_{e l}$, were determined from the measurements. The physical properties of the water-glycol solution, such as density, $\rho$, and specific heat capacity, $c_{p}$, were taken from a table. Moreover, each partial derivative $\partial R / \partial x_{i}$ was calculated by using the average values of the measured parameters. The systematic uncertainties of the measurements of the volumetric flow rate $\left(B_{V}\right)$, temperature $\left(B_{T w i}\right.$ and $\left.B_{T w e}\right)$, and electrical power $\left(B_{W e l}\right)$ are presented in Table 1 . The accuracies of the readings of the $c_{p}$ and $\rho$ are $\pm 1 \mathrm{~kJ} /(\mathrm{kgK})$ and $\pm 0.01 \mathrm{~kg} / \mathrm{m}^{3}$, respectively [11].

The results from the systematic uncertainty estimation of the results for $Q$ and $C O P$ are presented in Table 2. The $B_{C O P}$ decreases with the outdoor temperature increasing. Moreover, the consumed electrical power decreasing gives rise to a decline in the systematic uncertainty of COP. A similar result is reported in [11]. Therefore, the partial derivative $\partial C O P / \partial W_{e l}$ and accuracy of the electrical energy measurements have a major contribution to the results for $B_{C O P}$. Contrarily, there is no clear tendency in the variation of $B_{Q}$. It can be concluded that the systematic uncertainty in the $Q$ is around $12 \%$ when the external air temperature is in the range of $2.03^{\circ} \mathrm{C}$ to $11.13^{\circ} \mathrm{C}$. The noticeable slight increases in $B_{Q}$ can be explained by the fact that at certain values of the outside air temperatures (for example, $t_{e}=3.07^{\circ} \mathrm{C}, t_{e}=5.06^{\circ} \mathrm{C}, t_{e}=5.99^{\circ} \mathrm{C}$, and $t_{e}=7.9^{\circ} \mathrm{C}$ ) the difference in the temperature of the heat transfer medium in the supply and return pipe decreases due to the slight increase in the flow rate.

Table 2. Results from systematic uncertainty estimation of the mean values of the $Q$ and $C O P$.

\begin{tabular}{|c|c|c|c|c|}
\hline $\begin{array}{c}\text { Average external } \\
\text { air temperature }\end{array}$ & $\begin{array}{c}\text { Systematic } \\
\text { uncertainty of } \\
\text { COP }\end{array}$ & $\begin{array}{c}\text { Systematic } \\
\text { uncertainty } \\
\text { of Q }\end{array}$ & Mean COP & $\begin{array}{c}\text { Mean Q, } \\
\mathbf{k W} \pm \%\end{array}$ \\
\cline { 1 - 3 }$t_{e}\left[^{\circ} \mathrm{C}\right]$ & BCOP & $B Q$ & \\
\hline
\end{tabular}




\begin{tabular}{|c|c|c|c|c|}
\hline 2.03 & 0.0708 & 0.1208 & $2.421 \pm 7.1 \%$ & $4.58 \pm 12.1$ \\
\hline 3.07 & 0.0849 & 0.1241 & $2.475 \pm 8.5 \%$ & $4.42 \pm 12.4$ \\
\hline 4.03 & 0.0924 & 0.1198 & $2.727 \pm 9.2 \%$ & $4.30 \pm 11.98$ \\
\hline 5.06 & 0.0889 & 0.1238 & $2.858 \pm 8.9 \%$ & $4.07 \pm 12.4$ \\
\hline 5.99 & 0.1041 & 0.1247 & $3.237 \pm 10.4 \%$ & $3.90 \pm 12.5$ \\
\hline 7.00 & 0.1183 & 0.1241 & $3.461 \pm 11.8 \%$ & $3.68 \pm 12.4$ \\
\hline 7.90 & 0.1292 & 0.1242 & $3.477 \pm 12.9 \%$ & $3.35 \pm 12.4$ \\
\hline 8.99 & 0.1507 & 0.1222 & $3.548 \pm 15.1 \%$ & $2.90 \pm 12.2$ \\
\hline 9.92 & 0.1548 & 0.1217 & $3.505 \pm 15.5 \%$ & $2.73 \pm 12.2$ \\
\hline 11.13 & 0.1487 & 0.1168 & $3.406 \pm 14.9 \%$ & $2.65 \pm 11.7$ \\
\hline 11.78 & 0.1636 & 0.1098 & $2.804 \pm 16.4 \%$ & $2.10 \pm 10.98$ \\
\hline
\end{tabular}

\section{MATHEMATICAL MODELS OF THE PRODUCED HEAT POWER AND ENERGETIC COP}

As a result of collecting experimental data of the AWHP system, the experimental modeling of the produced heat transfer rate and energetic COP was carried out. These models are used as input data in Part 2 of the current investigation where the exergy and exergoeconomic assessment of the system is conducted.

The prediction of the produced heat transfer rate by the AWHP was implemented using linear regression of the experimental data. The measured mean values of the heat output rate were plotted as a function of external air temperature (Figure 5) and the obtained linear relationship is:

$$
Q_{i}=-0.2495 \cdot t_{e}+5.2602, k W
$$

To define the operating modes of the considered AWHP system, it is assumed that up to a certain external air temperature, the heat pump unit produces heat output that fully satisfies the requirements for the heating of the building. At this external air temperature (called bivalent temperature), the partial load ratio, $P L R=Q / Q_{\max }$, of the AWHP unit is equal to 1 . Otherwise, at outdoor air temperature equal to the balance temperature, $P L R$ is zero. Then, at $P L R=0$ the heat loss of the building is equal to the internal and external heat gains.

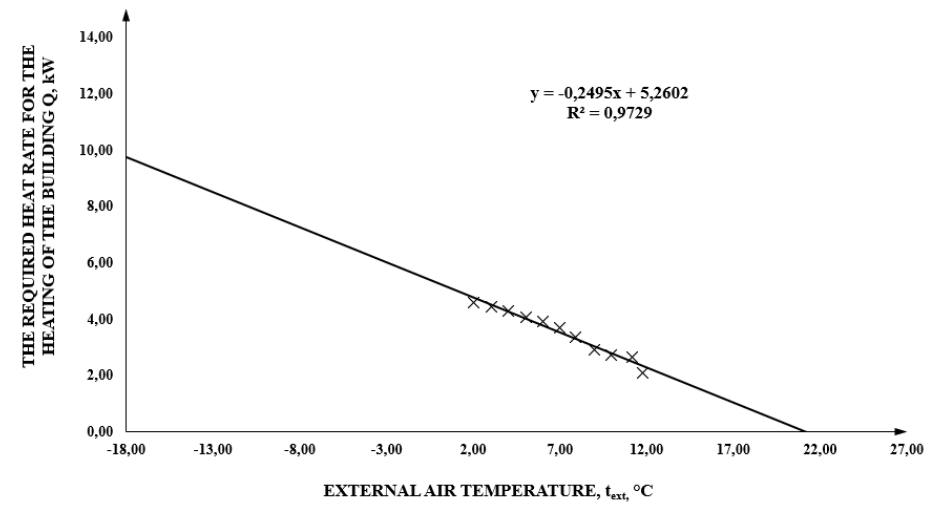

Fig. 5. Produced heat power by the AWHP as a function of external air temperature. 
Conducting a two-dimensional linear regression of the data for produced heat transfer rate at maximum inverter frequency, $Q_{\max , i}$, is obtained the equation:

$$
Q_{\mathrm{max}, i}=14.781+0.18175 \cdot t_{e}-0.15908 \cdot t_{w, e}, \mathrm{~kW}
$$

During the period of the experimental measurements, it was not observed conditions lead to the operation of the AWHP at maximum inverter frequency. As a result, the data for $Q_{\max }$ is according to the technical documentation of the unit [8].

According to the equations (6) and (7), the partial load ratio can be expressed as :

$$
P L R=Q_{i} / Q_{\max }=\frac{-0.2495 \cdot t_{e}+5.2602}{14.781+0.18175 \cdot t_{e}-0.15908 \cdot t_{w, e}}
$$

Therefore, from equation (7) can be state that the current AWHP system is characterized by the bivalent temperature $t_{b i v}=-5.73^{\circ} \mathrm{C}$ (at $P L R=1$ ) and the balance temperature is around $t_{\text {balance }}=21.08{ }^{\circ} \mathrm{C}$ (at $P L R=0$ ). The analysis of the technical data suggests that the AWHP will operate in on-off cycles when the PLR is less than 0.29 or at an external air temperature higher than $8.99^{\circ} \mathrm{C}$.

From Table 2 it can be seen that at external air temperatures higher than $t_{\text {on-off }}=8.99^{\circ} \mathrm{C}$, the mean values of COP slightly decrease. A significant drop is designated at $t_{e}=11.78^{\circ} \mathrm{C}$ (Table 2). These results can be explained by the on-off cycling energy losses. Moreover, in a previous study [12] was established that the electrical consumption during the on-off operation mode might exceed $12 \%$ of the overall electric energy consumed by the system due to the on-off cycling losses. The authors [12] supplement that these results are observed when an AWHP is sized to cover a large fraction of the design building peak load and the volume of the thermal storage is small. These prerequisites are present in the current case.

As a result of a limited number of measurements at outdoor external air temperatures higher than $8.99^{\circ} \mathrm{C}$, the on-off operation mode of the AWHP unit is not considered in the current paper and the followed exergetic and exergoeconomic analyses.

In conclusion, within the interval of values of the external air temperature $t_{e}=-5^{\circ} \mathrm{C} \div$ $8^{\circ} \mathrm{C}$, the AWHP will operate in partial load, and it will fully satisfy the requirements for the

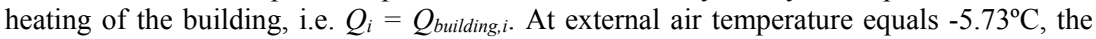
AWHP will operate at maximum inverter frequency.

The heat output rate of the considered AWHP unit is a function of the external air temperature, and the temperature of the produced heat transfer medium, $t_{w, e}$. Therefore, it is necessary to establish a procedure for analytical determination of $t_{w, e}$ as a function both of the required heat transfer rate for the heating of the building, $Q_{\text {bulding, } i}$, and external air temperature, $t_{e, i}$. This study suggests the using of the following expression $[13,14]$ :

$$
t_{w, e}=\left(\frac{Q_{\text {bulding }, i}}{N_{F C} \cdot Q_{F C, \text { nom }}}\right)^{\frac{1}{n}} \cdot \Delta T_{\text {nom }}+\frac{\sigma}{2}+\theta_{\text {int }, \text { des }}
$$

where:

$Q_{F C, \text { nom }}=5.7 \mathrm{~kW}$ - nominal heat transfer rate of fan coil units;

$Q_{\text {bulding, } i}$ - required heat transfer rate for the heating of the building at $i$-th external air temperature, $\mathrm{kW}$;

$N_{F C}=4$ - count of the fan coil units;

$\Delta T_{\text {nom }}=50 \mathrm{~K}$ - logarithmic meant temperature difference at standard conditions $\left(75^{\circ} \mathrm{C} / 65^{\circ} \mathrm{C} / 20^{\circ} \mathrm{C}\right)$;

$\sigma=5 \mathrm{~K}$ - design temperature difference between the temperature of the heat transfer medium in supply and return pipe; 
$\theta_{\text {int, des }}=21^{\circ} \mathrm{C}$ - design temperature of the indoor air;

$n=1.4$ - exponent to characterize the type of heat emission system (radiators, convectors, floor heating, etc.) [13].

Figure 6 illustrates the difference between the measured mean values of the temperature of the produced heat transfer medium and the calculated by equation (9) data for $t_{w, e}$. It was observed 11 test points were defined by the mean value of the external air temperature within a temperature bin $t_{e} \pm 0.5^{\circ} \mathrm{C}$. The average difference between the measured $t_{w, e}$ and the predicted values is around $3.6 \%$. The larger deviations can be noticed at lower outdoor air temperatures.

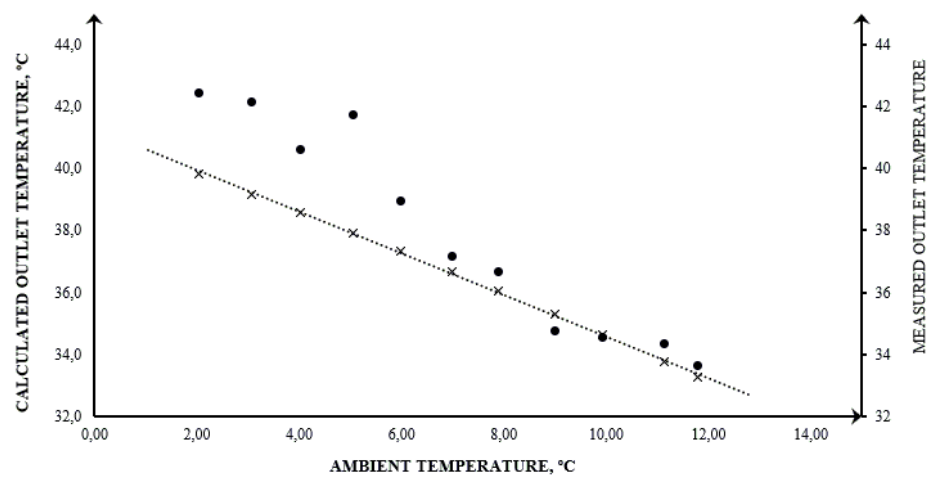

Fig. 6. Comparison of the measured and predicted outlet temperatures of the heat transfer medium.

In order to predict accurately energetic $C O P$ of the AWHP at partial load operating mode, the following mathematical model is used:

$$
C O P_{i}=\frac{P L R_{i}}{Z_{i}} \cdot C O P_{\max , i}
$$

where:

$P L R_{i}=Q_{i} / Q_{\max , i}-$ partial load ratio at $i$-th external temperature bin;

$Z=W_{e l, i} / W_{e l, \max , i}-$ the ratio of the consumed electrical power at part load operating mode and at full load (at the same outlet temperatures of the heat transfer medium, $t_{w, e}$ );

$C O P_{\max , i}$ - energetic coefficient of performance at $i$-th external temperature bin and $j$-th temperature of outlet heat transfer medium.

The conducted experimental measurements indicate a linear relationship between $P L R_{i}=Q_{i}$ $/ Q_{\max , i}$ and $Z=W_{e l, i} / W_{e l, m a x, i}$. The $Z$ was correlated in terms of PLR as shown in equation (11):

$$
Z=0.8332 \cdot P L R+0.1086
$$

A graphical representation of relationship from equation (11) is presented in Figure 7.

According to the equation (10) and (11), for energetic COP at partial operation mode can be formulate the expression:

$$
C O P_{i}=\frac{P L R_{i}}{0.8332 \cdot P L R+0.1086} \cdot C O P_{\max , i}
$$




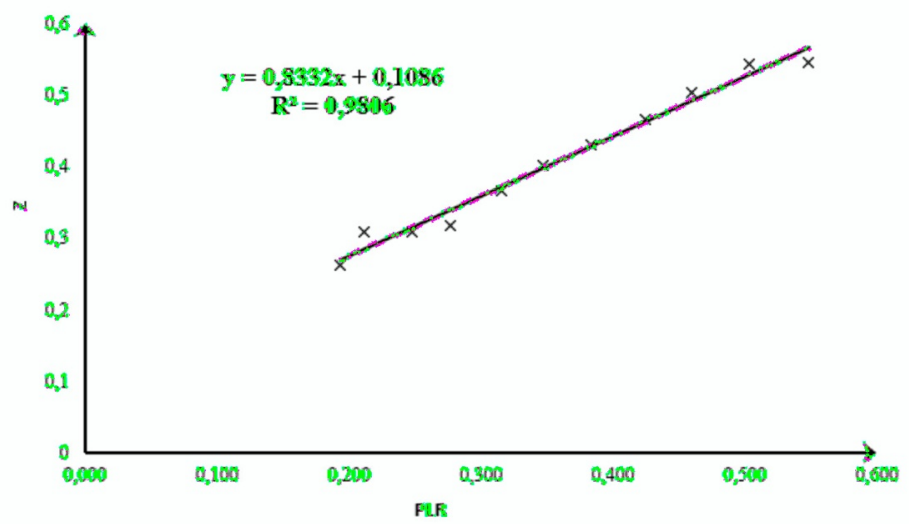

Fig. 7. $Z=W_{e, i l} / W_{e l, m a x, i}$ as a function of the partial load ratio $(P L R)$.

\section{Validation and verification of the obtained mathematical models}

The assessment of the adequacy and accuracy of all presented models was performed according to the rules of regression analysis.

First, the validity of the obtained regression model proved the high value of the coefficient of determination, $R^{2}\left(R^{2}=0.97\right.$ for the linear regression of $Q$ and $R^{2}=0.98$ for $Z$ ). On the other hand, the adjusted $R^{2}$ values are $96.7 \%$ and $97.8 \%$ in the case of the relationships of $Q$ and $Z$, respectively. Therefore, over $96 \%$ of the variance of $Q$ and $Z$ can be explained by the variance of the $t_{e}$ and $P L R$, respectively. In conclusion, the obtained mathematical models can be considered statistically significant.

In addition, using the tools of MS Excel is analyzed the variance of the suggested models. The obtained results are presented in Table 3 and Table 4.

Table 3. Results from analysis of variance of linear regression of $Q$.

\begin{tabular}{|l|c|c|c|c|c|c|}
\hline \multicolumn{1}{|c|}{ Parameter } & Coefficients & $\begin{array}{c}\text { Standard } \\
\text { Error }\end{array}$ & t- Stat & P-value & $\begin{array}{c}\text { Lower } \\
95 \%\end{array}$ & $\begin{array}{c}\text { Upper } \\
95 \%\end{array}$ \\
\hline Intercept & 5.2601 & 0.1063 & 49.48 & $2.8 .10^{-12}$ & 5.01968 & 5.500 \\
\hline$t_{e}$ & -0.2495 & 0.0139 & -17.97 & $2.3 .10^{-8}$ & -0.2809 & -0.218 \\
\hline
\end{tabular}

Table 4. Results from analysis of variance of linear regression of $Z=W_{e l, i} / W_{e l, \max , i}$.

\begin{tabular}{|l|c|c|c|c|c|c|}
\hline \multicolumn{1}{|c|}{ Parameter } & Coefficients & $\begin{array}{c}\text { Standard } \\
\text { Error }\end{array}$ & t- Stat & P-value & $\begin{array}{c}\text { Lower } \\
95 \%\end{array}$ & $\begin{array}{c}\text { Upper } \\
95 \%\end{array}$ \\
\hline Intercept & 0.1086 & 0.01458 & 7.448 & $3.9 .10^{-5}$ & 0.07562 & 0.142 \\
\hline$P L R$ & 0.8332 & 0.03907 & 21.33 & $5.15 .10^{-9}$ & 0.74477 & 0.922 \\
\hline
\end{tabular}

The results from Tables 3 and 4 designate that the intercepts in equations (6) and (11) are statistically significant at a $95 \%$ confidence level. This is evidenced by the results of $P$ values. In both cases, they are significantly lower than the assumed level of significance $\left(2.8 \cdot 10^{-12}<<0.05\right.$ and $\left.3.9 \cdot 10^{-5}<<0.05\right)$. Moreover, the slopes of the equations (6) and (11) are also statistically significant at a 0.05 level of significance.

As verification of the obtained models, a comparison of the calculated values for the $Q$ and $C O P$ through the measured data with those published by the manufacturer [8] is carried 
out. The results are shown in Figures 8 and 9. There is a little difference between the values of $Q$ obtained by the experiment and those declared by the manufacturer. These differences can be explained in part by the distinction in conditions at which the heat power was measured by the manufacturer [8]. Another possible explanation for this result is differences in the physical properties of the used heat transfer medium.

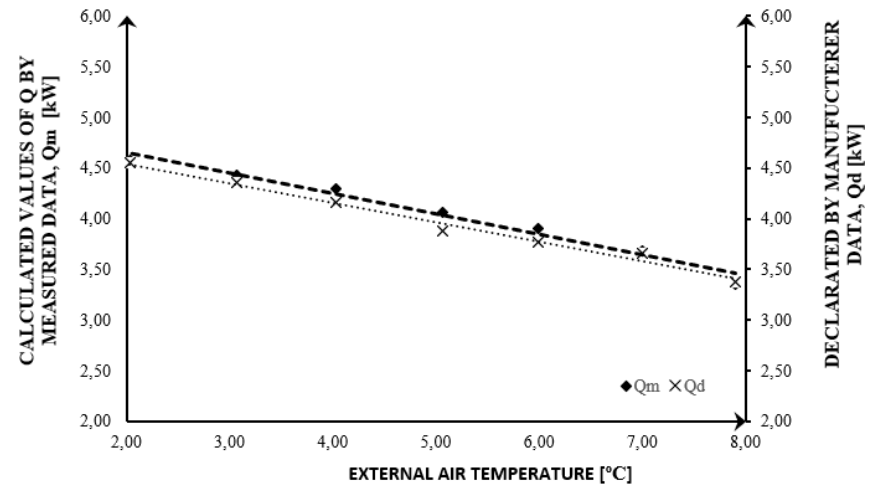

Fig. 8. Comparison of heat power determined using the measurement data, $Q_{m}$, and the values declared in [8], $Q_{d}$.

In [8] manufacturer presents the COP values characterized only by the AWHP, whereas in the current paper are presented the values for COP describe the whole system. Due to the lack of exact information about consumed electricity power by auxiliary equipment (fans, pumps, etc.) in the various operation modes of the system, in Figure 9 the values of COP obtained by the experiment are compared the data for COP of the unit at an outlet temperature of heat transfer medium equal to $45^{\circ} \mathrm{C}$ and minimum inverter frequency (15 $\mathrm{Hz}$ ). Thus, it is possible to assess the convergence of the obtained results. The experimental and declared data are approximated by a linear function. It can be concluded that the COP values determined using the measurement data have good convergence with declared in [8] values of the COP.

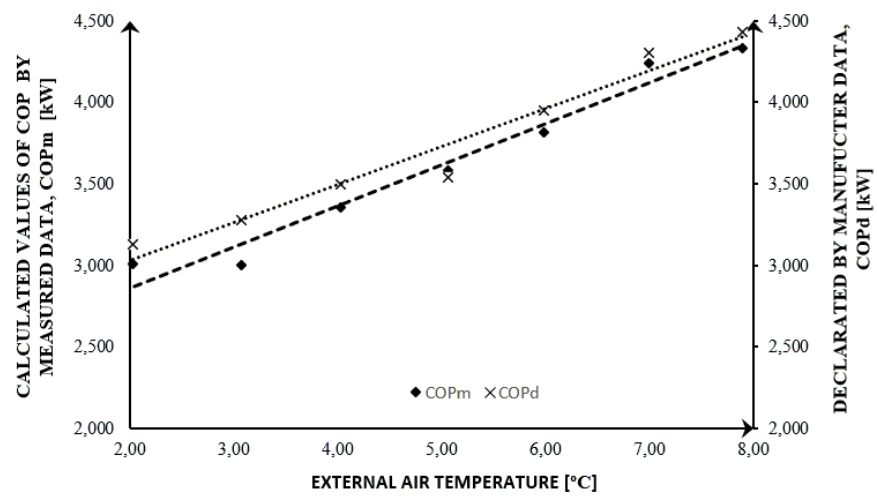

Fig. 9. Comparison of the $C O P$ values determined using the measurement data and the values declared in [8]. 


\section{Conclusions}

In Part 1 of the current investigation, an AWHP system was modeled and the obtained experimental results were evaluated. The objective of the paper was to establish the dependencies between produced power and energetic $C O P$ and dynamic changing ambient conditions. The developed mathematical models of $Q$ and $C O P$ are used are Part 2 of the investigation.

This study has identified that the system uncertainty value of $C O P$ is in interval \pm $(7.1 \div 16.4) \%$, whereas the system uncertainty of $Q$ varying in interval $\pm(10.98 \div 12.5) \%$. However, the conducted regression analyses confirmed the statistical significance of the regression models and their coefficients. In this case, it is not necessary to consider a larger number of measurements. It is proved that it is not necessary to add other parameters to the obtained models.

Moreover, an analytical procedure for the determination of the outlet temperature of the produced heat transfer medium is presented. It has proved that the obtained results about $t_{w, e}$ describe with high accuracy the actual behavior of the AWHP units with variable outlet. Therefore, the COP and $t_{w, e}$ models obtained in the current study for a particular application of the analyzed model AWHP unit can be used again in different applications of the same model heat pump.

The question raised by this study is how to achieve the maximum exergy content of the product of the AWHP system and is there a significant difference in the exergetic and exergoeconomic performance parameters of the AWHP system in different operations modes of the AWHP unit and backup heater. An attempt at a comprehensive answer to these questions is presented in Part 2 of the current investigation.

\section{References}

1. H. Zhao, E. Long, X. Zhang, Q. Liu, Z. Jin, F. Liang, Procedia Engineering 205, 2055 (2017).

2. G. Morrison, T. Anderson, M. Behnia, Sol Energy 76, 147 (2004).

3. J. Ji, G. Pei, T. Chow, W. He, A. Zhang, J. Dong, H. Yi, Appl Energ 80, 307 (2005).

4. Y. Ding, Q. Chai, G. Ma, Y. Jiang, Energ Convers Manage 45, 2393 (2004).

5. D. Wang, Y. Liu, Z. Kou, L. Yao L, Y. Lu, L. Tao, et al., Int J Refrig 106, 628 (2019).

6. P. Byrne, R. Ghoubali, Appl Therm Eng, 149, 414 (2019).

7. M. Ozturk, B. Doğan, L. Erbay, Sustain. Energy Technol. Assess., 42 (2020).

8. Mitsubishi Electric Corporation. Ecodan data book, 4 (2018), [Online], available at https://www.mitsubishi-les.info/database/servicemanual/files.

9. A. Rochim, Chauvenet's Criterion, Peirce's Criterion, and Thompson's Criterion (Literatures Review). 2nd Quantitative and Qualitative Analysis Course Homework, 21 March 2016.

10. A. Wheeler, A. Ganji Introduction to engineering experimentation (3rd Edition, Pearson, 2009).

11. A. Kahraman, A. Çelebi, Energies, 2, 697, (2009).

12. G.Bagarella, R.Lazzarin, M.Noro. Int J Refrig 65, 183, (2016).

13. prEN 15316-4-2:2006 Heating system in buildings - Method for calculation of system energy requirements and system efficiencies - Part 4-2: Space heating generation systems, heat pump systems.

14. St. Stamov, Heating, air conditioning and cooling handbook. Part II: Heat and gas supply, (Tehnika, Sofia, 2001). 